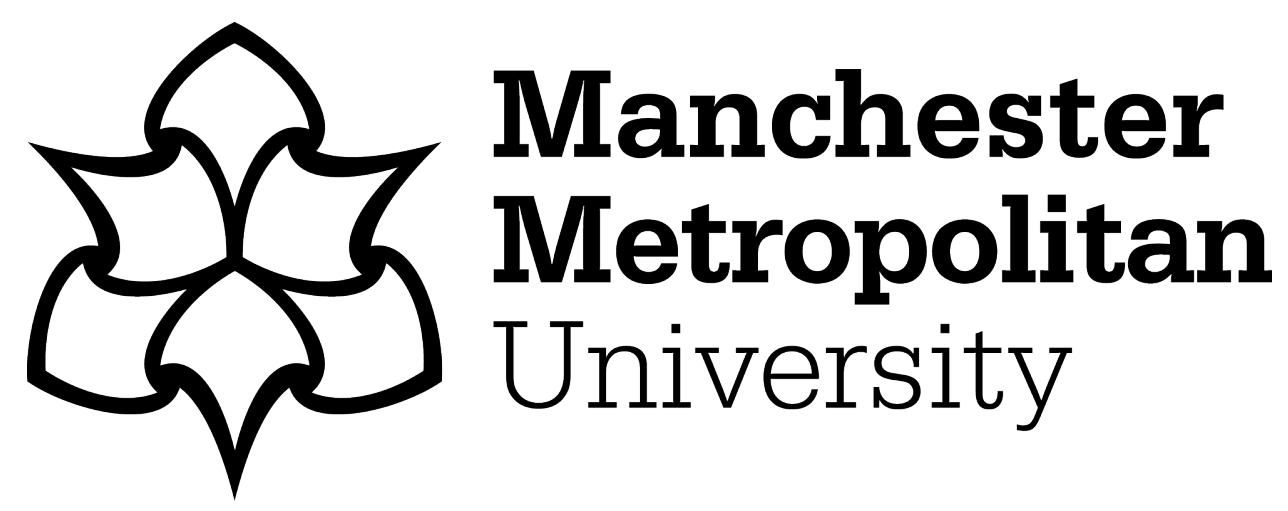

Allen, NS, McIntyre, R, Kerrod, JM, Hill, C and Edge, M (2018) PhotoStabilisation and UV Blocking Efficacy of Coated Macro and Nano-Rutile Titanium Dioxide Particles in Paints and Coatings. Journal of Polymers and the Environment, 26 (11). pp. 4243-4257. ISSN 1566-2543

Downloaded from: https://e-space.mmu.ac.uk/621881/

Version: Accepted Version

Publisher: Springer

DOI: https://doi.org/10.1007/s10924-018-1298-0

Please cite the published version 


\title{
Photo-Stabilisation and UV Blocking Efficacy of Coated Macro and Nano-Rutile Titanium Dioxide Particles in Paints and Coatings
}

\author{
Norman S. Allen ${ }^{1} \cdot$ Robert Mclntyre $^{2} \cdot$ Julie Maltby Kerrod ${ }^{2} \cdot$ Claire Hill $^{2} \cdot$ Michele Edge $^{1}$
}

Published online: 23 August 2018

○) Springer Science+Business Media, LLC, part of Springer Nature 2018

\begin{abstract}
Surface treated macro and nanoparticle $\mathrm{TiO}_{2}$ samples have been prepared, characterised and their efficiency as UV blockers evaluated in clear coatings and paints. The particle size of the 'base' $\mathrm{TiO}_{2}$ has been optimised to block UV radiation and the surface treatment developed to deactivate the photocatalytic activity of the surface of the $\mathrm{TiO}_{2}$ particles. The resultant UV blockers have been evaluated in both solvent and water-based clear coatings. Nanoparticle $\mathrm{TiO}_{2}$ has been prepared from 'seed' and the particle size was controlled by calcination. It was found that the choice of particle size is a compromise between UVA absorption, UVB absorption, visible transmission and photoactivity. It has been demonstrated that $\mathrm{TiO}_{2}$ with a crystallite size of $25 \mathrm{~nm}$ yields a product with the optimum properties. A range of dispersants was successfully used to disperse and mill the $\mathrm{TiO}_{2}$. Both organic and inorganic dispersants were used; 2-amino-2-methyl-1-propanol and 1-amino-2-propanol (MIPA) and $\mathrm{P}_{2} \mathrm{O}_{5}$ and $\mathrm{Na}_{2} \mathrm{SiO}_{3}$ respectively. The surface of the nano- $\mathrm{TiO}_{2}$ was coated with mixed oxides of silicon, aluminium, zirconium and phosphorous. Addition of the resultant coated nano-rutiles to an Isocyanate Acrylic clear coating prolonged the lifetime of that coating compared to the blank. Generally, a surface treatment based on $\mathrm{SiO}_{2}, \mathrm{Al}_{2} \mathrm{O}_{3}$ and $\mathrm{P}_{2} \mathrm{O}_{5}$ was more successful than one based on $\mathrm{ZrO}_{2}, \mathrm{Al}_{2} \mathrm{O}_{3}$ and $\mathrm{P}_{2} \mathrm{O}_{5}$. Higher addition levels of the surface treatment were beneficial for protecting the polymeric coating. The UV blocker products were also evaluated in a water-based acrylic, first a water-based dispersion of the UV blocker was prepared before addition to the acrylic. The dispersions and resultant acrylic thin films were evaluated using UV/Vis spectroscopy and durability assessed. The ratio of absorbance at 300:500 $\mathrm{nm}$ for the water-based dispersion was shown to be a good predictor of both the transparency of the resultant acrylic thin film and the durability of that film, in terms of weight loss. Macro grade titanium dioxide pigments were also prepared and coated with treatments of silica, alumina and siloxane and their photo-stabilising activity in alkyd paint film assessed and found to be directly related to the electron-hole pair mobility and trapping as determined by micro-wave spectroscopy.
\end{abstract}

Keywords Titanium dioxide $\cdot$ Surface treatments $\cdot$ Silica $\cdot$ Alumina $\cdot$ Acrylic paints $\cdot$ Nano-particles $\cdot$ Alkyd paints $\cdot$ Photooxidation · Degradation $\cdot$ Stabilisation

\section{Introduction}

Titanium dioxide exists in three crystalline modifications, rutile, brookite, and anatase, all of which have been prepared synthetically in various combinations and polymorphs
[1-10]. It has the highest average refractive index known. For anatase, it is 2.55 and for rutile it is 2.76 . These high values account for the exceptional light-scattering ability of pigmentary titanium dioxide when dispersed in various media, which in turns yields the high reflectance and hiding

Claire Hill

Claire.Hill@Cristal.com

1 Division of Chemistry, School of Science and the Environment, Faculty of Science and Engineering, Manchester Metropolitan University, Chester Street, Manchester M1 5GD, UK

2 Cristal Global, PO BOX 26, Grimsby, N.E. LINCS DN41 8DP, UK

Julie Maltby Kerrod

Julie.Kerrod@Cristal.com 
power, associated with it. The performance of a pigment in a surface coating is significantly affected by the interaction of the medium with the pigment surface. Treated $\mathrm{TiO}_{2}$ absorbs UV radiation and protects the polymer photochemically; untreated $\mathrm{TiO}_{2}$, however, is itself photocatalytic. Although it converts most of the UV energy into heat, the remaining energy creates radicals and other active species which accelerate the breakdown of the polymer. Virtually, almost all titanium dioxide used in plastics applications is surface treated. The most common surface precipitates are oxyhydrates of aluminium and silicon. Also used are oxides and oxy-hydrates of zirconium, tin, zinc, cerium, and boron. The treatment functions by placing a physical barrier between the pigment surface and the polymer matrix, blocking the active sites, and minimizing degradation. The treatment may also aid and reduce the requirements of power and shear when mixing. Many $\mathrm{TiO}_{2}$ pigments have also a final organic treatment, such as trimethylol propane or pentaerythritol. Some surface treatments also behave by deactivation of surface active species by an entrapment process.

During the manufacturing process of $\mathrm{TiO}_{2}$, the pigment is formed as discreet particles of around $0.2-0.4 \mu \mathrm{m}$. The titanium dioxide manufacturers control the operation variables to produce particles of a uniform size and distribution. These 0.2-0.4 $\mu \mathrm{m}$ particles have been engineered to maximize the scattering of light, resulting in optimum brightness and opacity.

Pure titanium dioxide possesses by nature an internal crystal structure that yields an innately high refractive index. When the particle size and particle size distribution is to be optimised so as to contribute along with its high refractive index to a maximum light scattering, conventional or pigmentary titanium dioxide is obtained. There exists, however, another type of titanium dioxide whose median crystal size has been explicitly reduced up to $0.02 \mu \mathrm{m}$. This is the socalled nanoparticles or ultrafine $\mathrm{TiO}_{2}$ and will be the main subject matter of this article as well as surface treated macro grades. The history of nanoparticle titanium dioxide dates to the late $70 \mathrm{~s}$ when the first patent on the preparation of these materials was issued in Japan. It is in principle possible to obtain nanoparticle $\mathrm{TiO}_{2}$ by simple milling of the pigmentary $\mathrm{TiO}_{2}$ to a finer particle [4]. However, the properties of the fine powders in terms of purity, particle size distribution and particle shape remain highly unsatisfactory.

$\mathrm{TiO}_{2}$ nanoparticles are also routinely produced by the gas-to-particle conversion in flame reactors because this method provides good control of particle size, particle crystal structure and purity [4]. Typically, the crystal size of these products is about a tenth of the size of the normal pigmentary grade. The smaller crystal size influences various properties and leads to higher values for the surface area and oil absorption. Lower values for specific gravity and bulk density are also achieved. Otherwise, it has many of the properties of conventional $\mathrm{TiO}_{2}$ pigments: non-toxic, non- migratory, inert, and stable at high temperatures. The optical behaviour of ultrafine $\mathrm{TiO}_{2}$ differs dramatically from that of conventional $\mathrm{TiO}_{2}$ pigments. The optical properties of nanoparticle $\mathrm{TiO}_{2}$ are governed by the Rayleigh theory of light scattering.

The complete picture of the optical behaviour of $\mathrm{TiO}_{2}$ becomes more complete by recognizing that $\mathrm{TiO}_{2}$ is a semiconductor. $\mathrm{TiO}_{2}$ exhibits a characteristic energy gap of $3.23 \mathrm{eV}$ or $3.06 \mathrm{eV}$ between the valence band and the conduction band for anatase and rutile, respectively. Wavelengths shorter than $390 \mathrm{~nm}$ for anatase and 405 for rutile-corresponding to higher energy than the threshold energy-will excite electrons from the valence to the conduction band. Summarizing, titanium dioxide exhibits various mechanisms under exposure to light depending on the wavelength and the particle size. Electron-hole pairs are formed giving rise to various sensitisation processes [9-17]. Based on the light scattering property described earlier, nanoparticle titanium dioxide can be used to impart excellent UV protection. Compared to the available UV absorbers, ultrafine nano- $\mathrm{TiO}_{2}$ possesses effective UV filter properties over the entire ultraviolet spectrum (UVC+UVB + UVA). For example, it is gaining a wide acceptance for use in sun creams. Nanoparticle $\mathrm{TiO}_{2}$, apart from its effective attenuating characteristics is extremely inert and therefore, safe to use next to the skin [5]. Nanoparticle $\mathrm{TiO}_{2}$ can also be used in clear plastic films to provide UV protection to foodstuffs. If particles of $\mathrm{TiO}_{2}$ are made small enough, so as to best scatter and absorb radiation in the UV part of the electromagnetic spectrum then maximum UV screening or blocking can be achieved.

It is also possible to use ultrafine $\mathrm{TiO}_{2}$ as a light stabilizer in plastics to protect the material itself from yellowing and to retard the deterioration of the mechanical properties. A further example of the potential of nanoparticle $\mathrm{TiO}_{2}$ as a UV filter is found in clear wood finishes. The original colour of wood panels can be retained by a clear lacquer made with $0.5-4 \%$ nanoparticle $\mathrm{TiO}_{2}$ [7]. In addition to preventing wood from darkening, ultrafine $\mathrm{TiO}_{2}$ also enhances its life-time.

The overall catalytic performance of titanium dioxide particles has been found to be dependent on quite number of parameters including preparation method, annealing temperature, particle/crystal size, the specific surface area, the ratio between the anatase and rutile crystal phases, light intensity, and the substrate to be degraded [9]. Furthermore, the electrons confined in the nanomaterial exhibit a different behaviour from that in the bulk materials. The properties of the electrons in small semiconductors should be dependent upon the crystallite size and the shape due to quantized motion of the electron and hole in a confined space. This phenomenon is called the quantum size effect. But the quantization effect 
does not exist in amorphous phases $[9,10]$. Due to this confinement, the band gap increases, and the band edges shift to yield larger redox potentials. So, the use of size-quantized semiconductor $\mathrm{TiO}_{2}$ particles may result in increased photoefficiencies [11]. However, other workers [12], reported that the photocatalytic activity increases significantly, and the blue shift was significant only at particle diameters less than $10 \mathrm{~nm}$. On the other hand, the small size effect can improve the photocatalytic activity of the $\mathrm{TiO}_{2}$ due to the increasing specific surface area which gives more reactive sites to absorb pollutants. Meanwhile, the diffusion of the photoinduced electrons or holes from bulk to surface becomes fast with a decrease in the particle size [13], which will also lead to an enhancement in the photocatalytic activity. On the other hand, the surface tension increases and causes a crystal lattice distortion with decreasing particle size [14] and consequent change in the structure of the energy band.

The $\mathrm{TiO}_{2}$ anatase phase is more active than the rutile phase in photocatalysis. The reason for the lower photocatalytic efficiencies in the rutile $\mathrm{TiO}_{2}$ phase is because the recombination of the electron-hole pair produced by UV irradiation occurs more rapidly on the surface of the rutile phase and the amounts of reactants and hydroxides attached to the surface of the rutile phase are smaller than those of the anatase $\mathrm{TiO}_{2}$ phase [15]. However, according to other work the decrease in the photocatalytic effect during the transformation from the anatase to rutile $\mathrm{TiO}_{2}$ phase was not due to the change in the crystalline structure, but mainly due to changes in the specific surface area and porosity [16]. While more recent studies have shown that the photoactivity of nano-titanium dioxide is highly dependent upon its preparation and thermal history which in turn controls the formation of mixed polymorphs through anatase-brookiterutile $[1-3,6,10]$. In many cases photoactivity is controlled by the presence of the brookite. The latter is supposed to cause a cationic shift in the Titania absorption band $[2,3]$. The photocatalytic processes on a titanium dioxide particle are displayed in Fig. 1. Primarily following photo-excitation a number of surface processes can take place providing activation and further reactions depending upon the nature of the environment in question. Holes can generate active hydroxyl radicals while active oxygen species are generated through electron transfer processes. All exhibit high activity that can react with surrounding organic and gaseous environments. The presence of alumina/silicate coatings for example, shown in this figure will trap out surface generated electrons thus minimising the production of active surface species which can degrade the polymer materials. Sunlight photolytic degradation and/or photooxidation can only occur when the polymer contains chromophores which absorb wavelengths of the sunlight spectrum on earth $(>290 \mathrm{~nm})$. These wavelengths have sufficient energy to cause a dissociative (cleavage) processes resulting in degradation.

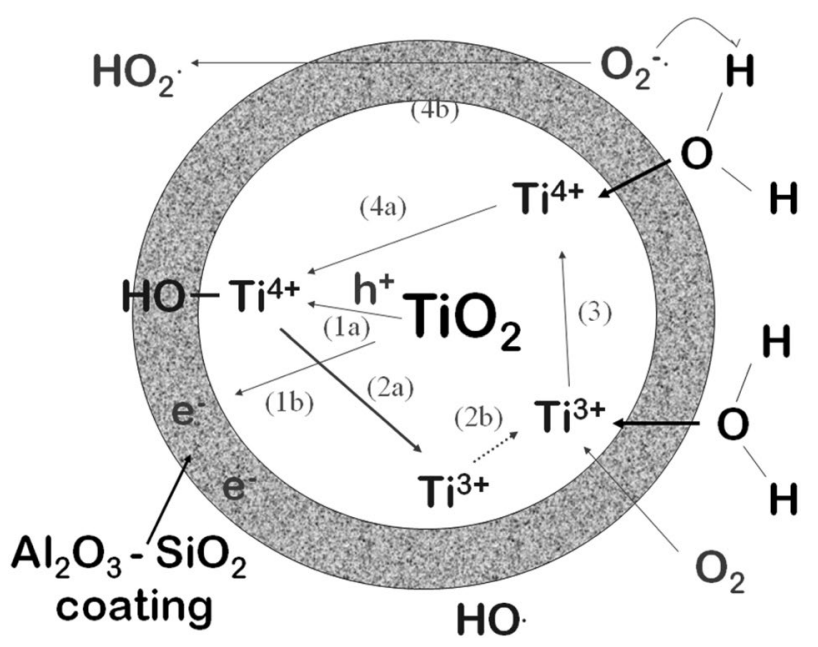

Fig. 1 Surface photocatalytic activity of titanium dioxide

As well as deactivating the surface, the surface coating also provides other benefits to the finished $\mathrm{TiO}_{2}$ product (both pigmentary and nanosized) such as the processability of the treated product during manufacturing and the ease of dispersion of that dried product into media such as a paint. Once the surface coating has been added to the $\mathrm{TiO}_{2}$, the product must be filtered and washed free of the salts formed in the treatment process and then dried. The surface treatment effects these processing steps; $\mathrm{TiO}_{2}$ with an outer coating of $\mathrm{Al}_{2} \mathrm{O}_{3}$ will filter much more quickly than one with an outer layer of $\mathrm{SiO}_{2}$ for example. The wetting of titanium dioxide agglomerates into their final application such as a resin or solvent can be made easier by the presence of appropriate inorganic and organic surface treatments. This can be achieved by using the acid base interaction, or by covering the $\mathrm{TiO}_{2}$ surface with an organic substance that is chemically similar to the dispersing liquid. Both of these techniques work by reducing the interfacial tension; furthermore, organic surface treatments reduce the packing density of the primary particles in the agglomerates [18].

In this extensive study an optimum particle size grade of rutile nano-titania is developed and analysed for UV blocking/scattering performance. The optimum grade is then coated with various surface treatments of silicate, phosphate, zirconates and organics at various levels and their properties as effective UV blockers determined in acrylic and isocyanate-acrylic coatings by a variety of test methods during artifical weathering including UV spectroscopy, weight loss and $60^{\circ}$ loss. The effect of pre-surface treatments are also examined here on rutile particle activity (pre-treatments before the actual coating is applied and not previously studied in the literature). Macro grade titania pigments were also prepared and coated with treatments of silica, alumina and siloxane and their photostabilising activity in alkyd paint film assessed and found to be directly related to the 
electron-hole pair mobility as determined by micro-wave spectroscopy $[19,20]$. The data is related to the photoactivity of the prepared Titania particles using the standard isopropanol to acetone oxidation test confirming its viability [21]. Although it is known that surface treatments have a protective effect detailed analysis and pre-/post-surface treatments especially on nano-rutile particles has not previously been undertaken. The outcome of this investigation provides valuable novel information on the role of the various surface treatments on nano-grade photoactive rutile particles and their relative effectiveness in inhibiting the surface active species on Titania particles in commercial coatings systems vs. their ability to act as effective UV blockers. It also extends our previous extensive earlier investigations on the role of macro and nano rutile particles in polyethylene and isocyanate coating systems [22] where nano-particles are highly active but their activity can be controlled by admixing with macro-coated rutile pigments at various levels.

\section{Experimental}

\section{Titanium Dioxide Samples}

\section{Preparation of 'Base' $\mathrm{TiO}_{2}$}

The starting material for the preparation of nanoparticle $\mathrm{TiO}_{2}$ made here is the "seed" used in the process of manufacturing the rutile pigment. Seed can be described as a hydrated titanium dioxide obtained from the thermal hydrolysis of titanium oxy-sulphate. $\mathrm{This}^{\mathrm{TiO}_{2}}$ gel is then digested using concentrated $\mathrm{NaOH}$ solution to produce sodium titanate. This is then washed (to remove soluble sulphate and sodium ions) and reacted with either $\mathrm{TiCl}_{4}$ or $\mathrm{HCl}$. This results in a suspension of rutile needles in $\mathrm{HCl}$. The suspension is then neutralised to flocculate the particles; $\mathrm{NaOH}$ or $\mathrm{NH}_{4} \mathrm{OH}$ can be used at this stage. The particles are then filtered and washed to remove the chloride ions, oven dried and finally calcined to give the desired particle size and specific surface area, which are controlled by calcination temperature and duration. Determination of the relationship between calcination temperature and particle size has been established by preparing samples by the method described above and calcining at a range of temperatures between 370 and $700{ }^{\circ} \mathrm{C}$ for $1 \mathrm{~h}$. B.E.T. surface areas and size determination by XRD was carried out on the resultant $\mathrm{TiO}_{2}$ products.

Macro titanium dioxide samples (RCL Grade) were coated and supplied by Cristal Global with organic (Siloxane), $\mathrm{SiO}_{2}(1.5 \% \mathrm{w} / \mathrm{w}), \mathrm{Al}_{2} \mathrm{O}_{3}(3.5 \% \mathrm{w} / \mathrm{w})$, organic (Siloxane $)+\mathrm{SiO}_{2}(1.5 \% \mathrm{w} / \mathrm{w})+\mathrm{Al}_{2} \mathrm{O}_{3}(3.5 \% \mathrm{w} / \mathrm{w}), \mathrm{SiO}_{2}(3.5 \%$ $\mathrm{w} / \mathrm{w})+\mathrm{Al}_{2} \mathrm{O}_{3}(1.5 \% \mathrm{w} / \mathrm{w})$. These were incorporated and dispersed into the Alkyd and Acrylic based paint films as described below. Nano particle samples of titanium dioxide were also prepared and supplied at 15, 25, 35 and $45 \mathrm{~nm}$. These were examined for UV activity for optimisation study and coating. A disc centrifuge was employed to measure the mean particle size and the standard deviation of the particle size distribution of the $\mathrm{TiO}_{2}$ in each of the dispersions.

\section{Surface Treatments}

The alumina was precipitated onto the surface of the $\mathrm{TiO}_{2}$ in the following way; an aqueous alkaline slurry of $\mathrm{TiO}_{2}$ was prepared and heated to $60^{\circ} \mathrm{C}$, alumina was then added from a solution of sodium aluminate $\left(\mathrm{Al}_{2} \mathrm{O}_{3}\right.$ is soluble above $\mathrm{pH}$ 9.2). When the $\mathrm{pH}$ of the $\mathrm{TiO}_{2}$ slurry containing, the sodium aluminate is neutralised with an acid, for example, Hydrochloric acid, the $\mathrm{Al}_{2} \mathrm{O}_{3}$ precipitates out of the aluminate solution and onto the surface of the $\mathrm{TiO}_{2}$ since it is no longer soluble below pH 9.2.

\section{$\mathrm{SiO}_{2}, \mathrm{Al}_{2} \mathrm{O}_{3}, \mathrm{P}_{2} \mathrm{O}_{5}$}

The surface treatment consisted of a layer of silicon dioxide, precipitated from a solution of sodium silicate using dilute hydrochloric acid. A layer of phosphate was then added from sodium hexametaphosphate followed by a top layer of aluminium oxide precipitated from a solution of sodium aluminate using hydrochloric acid.

\section{$\mathrm{ZrO}_{2}, \mathrm{Al}_{2} \mathrm{O}_{3}, \mathrm{P}_{2} \mathrm{O}_{5}$}

The surface treatment consisted of a layer of phosphate from a solution of sodium hexametaphosphate, followed by a layer of zirconium oxide precipitated from zirconyl chloride and finally a layer of aluminium oxide from a solution of sodium aluminate. Once the mixed oxides were precipitated from solutions onto the $\mathrm{TiO}_{2}$ surface, the resulting slurry was filtered and washed with demineralised water to remove the sodium chloride generated during the neutralisation reactions. Once de-watered, the filter cake was blended with Trimethylolpropane (TMP) in a Kenwood chef food mixer. The TMP aids the micronisation as well as dispersion of the dry finished $\mathrm{TiO}_{2}$ in the end applications such as paint. The treated $\mathrm{TiO}_{2}$ was dried at $120{ }^{\circ} \mathrm{C}$ overnight, crushed through a sieve with a mesh size of $1.4 \mathrm{~mm}$ and micronized using a 3 in (grinding ring diameter) air microniser. Injection and grind ring pressures were 135 and 125 psi respectively and the $\mathrm{TiO}_{2}$ was fed to the microniser at a rate of $15 \mathrm{~g} / \mathrm{min}$.

\section{Paint Formulations}

The alkyd paint formulation used is based on an 18\% PVC air drying long oil alkyd based on commercial Sobral P470 supplied by the Scott Bader Company Ltd., Wellingborough, Northants, UK. The paint drier is a commercial Manosec 
CD33 supplied by Rhone Poulenc Chemicals, Manchester, UK while the methyl ethyl ketoxime was supplied by Banner [Samuel] \& Co. Ltd., Liverpool, UK. The resin and white spirit are initially mixed and then dispersed at $2000 \mathrm{rpm}$ using a Dispersmat AE3-C with $50 \mathrm{~mm}$ diameter impellor for $30 \mathrm{~min}$ (until no striations are seen). The pigment is then added to the dispersion that is then ball-milled using steatite balls in Melinex capped glass jars. The milled base was then let down using the formulation shown and agitated for $10 \mathrm{~min}$ using the Dipsersmat and then placed on the rollers for $15 \mathrm{~min}$ followed by a $15 \mathrm{~h}$ stabilisation period. The paint films (coated on stainless steel plates for accelerated weathering and aluminium plates for natural exposures) were conditioned for 10 days at $40{ }^{\circ} \mathrm{C}$ to remove any trapped solvent.

The water based acrylic wood stain formulation as supplied by Rohm and Haas is based on Part A (Primal AC-337 (61.3 g), BYK-024 (0.1 g), water (75 g), Texanol (2.3 g) and ammonia (0.3 g)) and Part B (water (95 g), Acrysol 2020 (3.5 g) and Acrysol RM-12W(12 g)). Part A is mixed with the appropriate amount of Titania particles and additives using a laboratory stirrer for $10 \mathrm{~min}$. Part B (50\% w/w) was then added and mixed for a further $5 \mathrm{~min}$. The prepared paints were then applied to stainless steel panels for testing for gloss and weight loss during ageing. Samples were also applied to aluminium plates via a $15 \mu \mathrm{m}$ K-bar with a drying period of $24 \mathrm{~h}$ between the coats.

The isocyanate water based acrylic paint (clear auto-finish) was formulated and supplied by Bayer, Germany, siliconised polyester paint from DSM, Netherlands. An ambient curing two pack polyurethane clear coating based on isocyanate and acrylic resins was used. Once the paints were prepared, they were drawn-down onto Melinex/cellophane substrates and allowed to dry. The thickness of these films was measured using a gauge.

\section{Techniques}

\section{X-Ray Diffraction Spectrometry (XRD)}

Both the primary crystallite size of the nano-sized materials and the crystal phase of $\mathrm{TiO}_{2}$ present were determined using a Philips PW 1830 diffractometer. The XRD pattern is indicative of the crystal phase and the crystallite size was calculated using Scherrers equation taking the full widths at half maximum (FWHM), which is generally an accepted method to estimate the mean crystallite size [22]. From the line broadening of corresponding X-ray diffraction peaks and using the Scherrer formula the crystallite size was estimated as follows in Eq. 1:

$L=\frac{K \lambda}{\beta \cos \theta}$ where $\lambda$ is the wavelength of the $\mathrm{X}$-ray radiation $(\mathrm{CuK} \alpha=0.15406 \mathrm{~nm}), \mathrm{K}$ is a constant taken as $0.89, \beta$ is the line width at half maximum height, and $\theta$ is the diffracting angle.

\section{BET Surface Area}

The specific surface area of $\mathrm{TiO}_{2}$ can be determined using the B.E.T. (Brunauer Emmett Teller) method. The equipment used was a Coulter SA3100. The B.E.T. equation can be written in the linear form as follows in Eq. 2:

$\frac{\mathrm{P} / \mathrm{P}_{\mathrm{s}} \mathrm{u}}{\mathrm{a}\left(1-\mathrm{P} / \mathrm{P}_{\mathrm{s}}\right)}=\frac{1}{\mathrm{a}_{\mathrm{m}} \mathrm{C}}+\frac{\mathrm{C}-1}{\mathrm{a}_{\mathrm{m}} \mathrm{C}} \cdot \frac{\mathrm{P}}{\mathrm{P}_{\mathrm{s}}}$

where $\mathrm{C}$ is a constant related to the free energy adsorption in the monlayer, $\mathrm{p}$ is the pressure of the adsorbate vapour, the amount adsorbed of which is $\mathrm{a}, \mathrm{P}_{\mathrm{s}}$ is the saturated vapour pressure of the adsorbate at the adsorption temperature and $\mathrm{a}_{\mathrm{m}}$ the monolayer capacity of the surface. In the B.S.I. BET method [18] the adsorption of nitrogen is measured at its boiling point at $\mathrm{P} / \mathrm{P}_{\mathrm{s}}$ values between 0.05 and 0.3 . From the slope and intercept of a plot of the left-hand side equation against $\mathrm{P} / \mathrm{P}_{\mathrm{s}}$, values of $\mathrm{C}$ and $\mathrm{a}_{\mathrm{m}}$ can be evaluated. The value of $\mathrm{a}_{\mathrm{m}}$ (in appropriate units) is converted to the specific surface area (usually expressed in $\mathrm{m}^{2} / \mathrm{g}$ ) by assuming the molecular area of nitrogen to be $0.1623 \mathrm{~nm}^{2}$.

\section{Transmission Electron Microscopy (TEM)}

$\mathrm{TiO}_{2}$ particles were assessed using a Philips CM10 conventional Transmission Electron Microscope. The $\mathrm{TiO}_{2}$ was first dispersed in Isopropyl alcohol and then dropped onto a carbon support film on a copper grid before analysis. Viewing the samples in this way allows a physical means of determining the particle size, shape and the added surface treatment.

\section{CPS Disc Centrifuge}

This instrument separates the particles under evaluation by size using centrifugal sedimentation in a liquid medium. The sample is contained within a clear spinning disc. Particles of different sizes settle at different rates according to Stokes' Law, so that as the particles reach the edge of the disc they block/scatter the light of the detection beam which is monitored throughout the test. CPS centrifuge model DC12000. 


\section{Qualitative and Quantitative Determination of Surface Treatments}

\section{Inductively Coupled Plasma-Optical Emission Spectroscopy (ICP-OES)}

The samples were dissolved in hydrofluoric acid, diluted, and then analysed using a Perkin Elmer Optima 3000 DV.

\section{X-Ray Fluorescence Spectroscopy (XRF)}

The $\mathrm{TiO}_{2}$ samples were pressed into a plug which was then analysed for composition using a Philips PW2404 X-ray spectrometer.

\section{Fourier Transform Infra-Red Spectroscopy (FTIR)}

A Perkin Elmer Spectrometer 2000 was employed to determine the organic additives on the $\mathrm{TiO}_{2}$ samples.

\section{Isopropanol Oxidation Test}

When $\mathrm{TiO}_{2}$ is irradiated with UV light, hydroxyl radicals are generated, which are responsible for the oxidation of isopropanol, which is the basis of this test. Samples in sealed Pyrex cells were exposed to a UV light source (100 W High Pressure Mercury lamp $365 \mathrm{~nm}$ filtered) for a period of $5 \mathrm{~h}$, stirred and the amount of acetone generated during the reaction was recorded. The larger the amount of acetone generated the more photoactive the $\mathrm{TiO}_{2}$ [21]. This is a well reported assessment technique for photoactivity.

\section{Accelerated Weathering}

The coated panel samples and plates were exposed in an ATLAS Ci65A accelerated weathering machine. UV irradiance was $0.4 \mathrm{~W} @ 340 \mathrm{~nm}$ and the black panel temperature was $63{ }^{\circ} \mathrm{C}(50 \% \mathrm{RH})$. The test panels were sprayed with water for a period of $12 \mathrm{~min}$ in every 120 to simulate the effect of rainfall. Weight loss of the coatings were monitored over the exposure period to assess the coatings durability.

\section{Microwave Technique}

Microwave measurements were undertaken using a Marconi (6200A) 2-20 GHz programmable sweep generator and automatic amplitude analyser, coupled to a circular waveguide and cylindrical cavity as reported previously $[19,20]$. Powdered samples $(0.2 \mathrm{~g})$ were packed in the bottom of the cavity on a plastic dish (to ensure reproducibility) and were irradiated in the cell chamber with an ILC 302UV xenon source via an optical fibre set-up (Laser Lines Ltd., Beaumont Close, Banbury, Oxon, U.K) switchable between UV and visible light with a cut-off point at $400 \mathrm{~nm}$. In this work visible light only was used as the UV response is weak for the Titania pigments. Changes in microwave cavity resonant frequency and attenuation of microwave power were monitored during 1800s of irradiation and for 1800s after switching off the light source (unless stated otherwise). All measurements were carried out in triplicate, and at $25^{\circ} \mathrm{C}$. The uncertainty in the values of 'shift in microwave cavity resonant frequency' is of the order $\pm 0.0004 \mathrm{GHz}$; while that for 'attenuated power' is $\pm 0.05 \mathrm{dBm}$.

\section{Results and Discussion}

\section{Macro Coated Titanium Dioxide and Microwave Analysis Versus Alkyd Paint Degradation}

Many investigators have established that $\mathrm{TiO}_{2}$ photo-catalytically degrades paint films (as well as thermoplastics), using ultraviolet light to convert oxygen and free radicals that oxidize and degrade the polymeric binder (see above scheme in Fig. 1).

According to the scheme above, one water molecule and one oxygen molecule are converted into one hydroxyl and one perhydroxyl radical at the surface of the $\mathrm{TiO}_{2}$ when irradiated with UV, these radicals are responsible for the degradation of the surrounding polymer [23, 24]. Water, oxygen and UV are all required for the photocatalytic degradation of the polymer to take place, since none of the components can be eliminated from an exterior environment in which the surface coating may be placed. Protection of the polymer must be brought about by a different mechanism, one is to prevent the UV radiation being able to cause the photocatalytic degradation in the first place. This can be obtained by carefully choosing a $\mathrm{TiO}_{2}$ pigment which has been suitably photostabilised by coating with inorganic oxides.

A significant loss of gloss is usually recorded before chalking is observed. Gloss is a measurement of the reflection from the surface of a visible beam of light in relation to a standard black glass surface. Both gloss loss and chalking are recognised and accepted as being an accurate indication of the degree of breakdown of a paint film or polymeric coating.

The prepared and coated macro rutile pigments were dispersed into an alkyd paint as described and coatings weathered in the Atlas. Weight loss with time was determined and the data related to the photoactivity (or photostability) of the pigment particles as measured by micro-wave spectroscopy. In this technique microwaves are directed, via a wave-guide, through an aperture into a cavity. At certain frequencies the cavity abstracts appreciable power, since the oscillating electric and magnetic fields of the microwave energy reach a maximum when they are resonant with the 
cavity. Typical microwave spectral changes for a selection of the anatase pigments used here with respect to that for the cavity are shown in Fig. 2. The amount of energy stored by a microwave cavity is known as its quality factor (Q-factor). When a sample is placed in the cavity and exposed to UV/ visible light the position of the resonant frequency shifts and microwave power is attenuated.

The data depicted relates to the exposure and microwave conductivity response of the titanium dioxide powders. Figure 2 shows that, during irradiation, the attenuation in microwave power is greater in the presence of the surface coatings on the rutile pigments. This is consistent with a reduction in free-carrier population and enhanced trapping as in the case of the more heavily coated grade. The data depicted relates to the exposure and microwave conductivity response of the titanium dioxide powders. The positive shift in resonant frequency on irradiation arises from excess carrier formation, following saturation of traps, during prolonged exposure. However, pigments with silica coatings after a fast-initial rise in carrier production displays a strong plateau due to strong trapping followed by a sharp dark decay to the valence state after extinguishing the light source due to carrier recombination (shown as the blip in the curves). No such rapid dark recombinations were evident in the case of the silica coated pigments and that with the triple coating. This would certainly account in part, for the apparent lower photoactivity of these pigments. The dark recombination processes in the pigments suggests that excess carriers are trapped in deep lying states giving rise to the observed longlived residual frequency component in the decay process. Thus, the particular coating used here has a major influence on carrier generation and hole trapping. In all, measurements on microwave dielectric properties of titania pigments provides a useful and more versatile tool for the assessment of their photoactivity extended to a polymer matrix. The shift in microwave cavity frequency illustrates similar behaviour

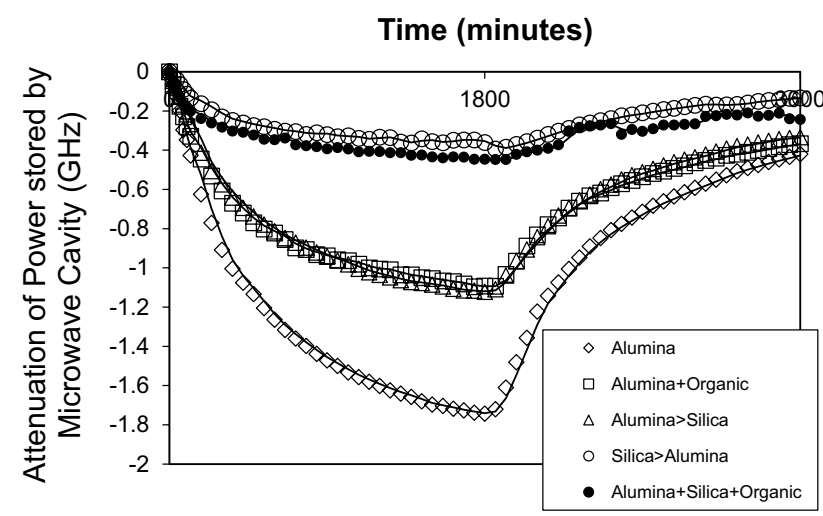

Fig. 2 Attenuation of microwave power (GHZ) for each of the prepared coated macro-titania powders under irradiation and switch off showing recombination of carriers with rapid carrier generation in the alumina coated pigments followed by a slow dark decay due to deep lying long-lived carrier states or species (Fig. 3). Silica is seen to be the most active carrier quencher (electron-hole trapping) and is synergistic with a combination alumina and organic coatings.

Figure 4 shows a plot of the shift in the microwave cavity resonant frequency vs. the weight loss of the paint films containing the different rutile pigments. The linearity of the relationship is clear evidence of the carrier mobility and trapping efficacy of the coatings on the control of the rutile durability.

\section{Nano-rutile}

\section{Optimisation of Nano-particle Rutile Size}

Samples of nano-rutile $\mathrm{TiO}_{2}$ with different crystallite sizes were prepared and correlated with calcination temperature and particle sizes obtained and tested were 15, 25, 35 and

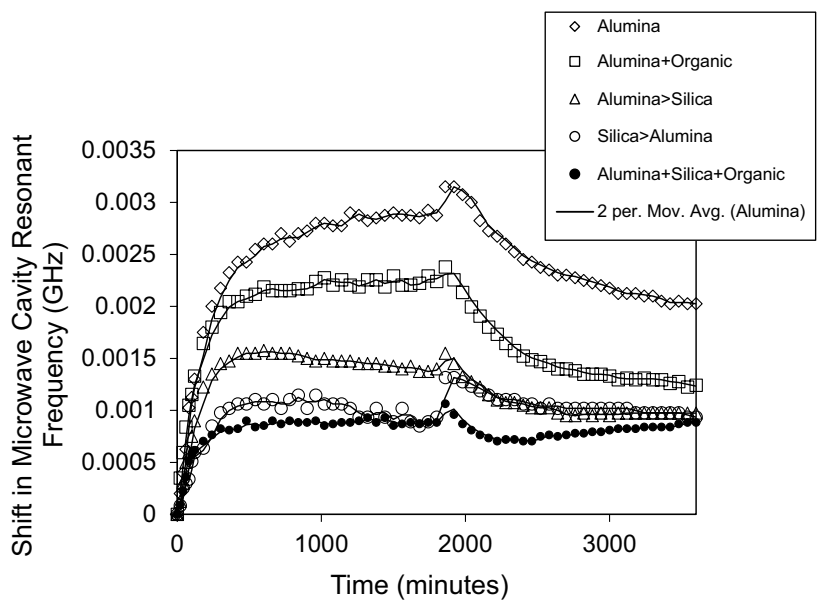

Fig. 3 Shift in microwave cavity frequency (GHZ) under illumination followed by switch off showing decay of carriers

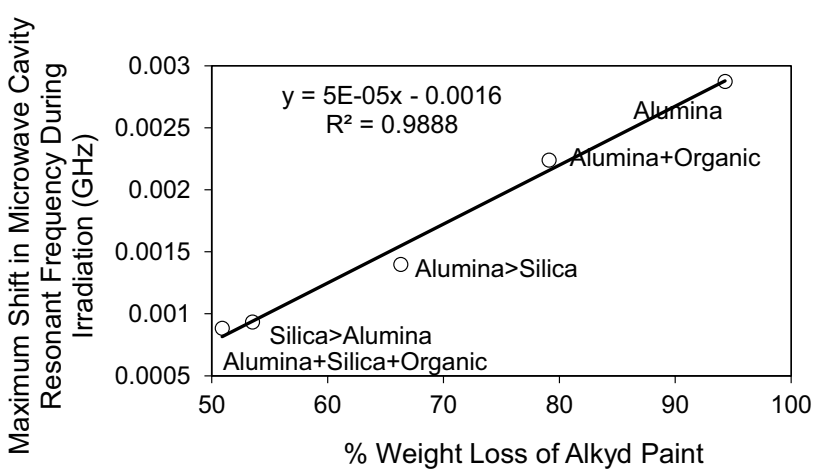

Fig. 4 Maximum shift in microwave resonant frequency during irradiation in the cavity versus weight loss of the alkyd paint during weathering 
$45 \mathrm{~nm}$. These samples of base $\mathrm{TiO}_{2}$ were added to a clear isocyanate acrylic coating at a level of $2 \%$ on resin solids. The UV/Visible absorption of the films were then recorded. The molar extinction coefficient has been used to compare the samples to take into account slight variations of film thickness between the samples (thickness of the film is the path length).

From the spectra the UVA absorption (315-400 nm) was found to increase with increasing crystallite size, up to $35 \mathrm{~nm}$, at $45 \mathrm{~nm}$ this starts to reverse (Fig. 5). UVB absorption (280-315 nm) also increases with size, again up to a maximum at $35 \mathrm{~nm}$. Visible transmission $(400-700 \mathrm{~nm})$ decreased with increasing size.

The $45 \mathrm{~nm}$ sample appears to behave differently both in terms of UV absorption and visible scattering. The particles are probably too large to obey Rayleigh's light scattering theory, and also begin to behave more like pigmentary particles. Of course, the possibility of a poorer state of dispersion with the larger particles should also not be overlooked as a reason for this apparent change in the interaction with light. A good dispersion should lead to more efficient light blocking of the particles. It has been reported that $\mathrm{TiO}_{2}$ which is not well dispersed does not offer protection to a polymer matrix against photodegradation [25, 26]. A small particle size means a large surface area, and therefore potentially a large photoactive surface. The photoactivity of these $\mathrm{TiO}_{2}$ samples with various sizes, was evaluated; the isocyanate acrylic coatings were applied to stainless steel panels and exposed in an ATLAS accelerated weathering machine. The weight loss of the coating was measured against exposure time and the results are shown in Fig. 6.

Generally, the smaller the $\mathrm{TiO}_{2}$ used, the higher the weight loss recorded. It is suggested that this is due to the larger surface area available for UV light induced

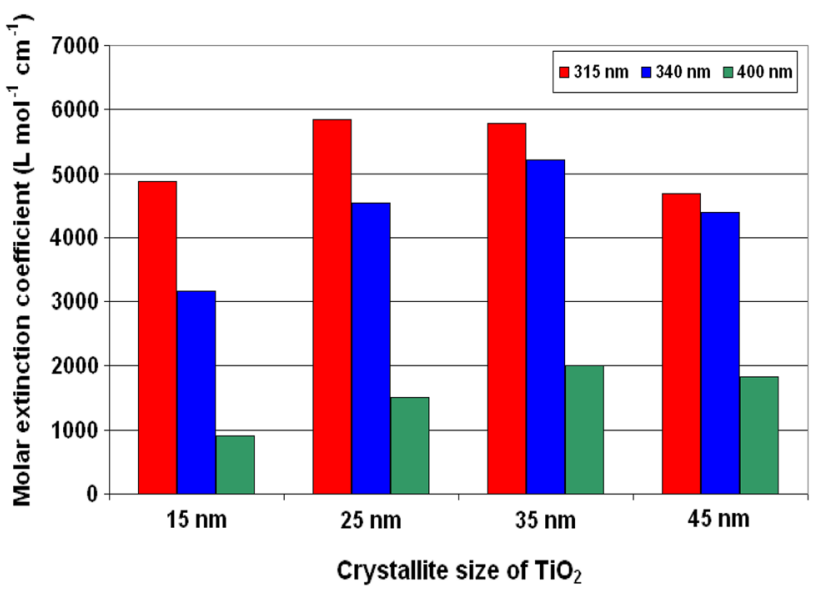

Fig. 5 Molar extinction coefficient for $\mathrm{TiO}_{2}$ of various crystallite sizes at various wavelengths. Thin films of isocyanate acrylic containing $\mathrm{TiO}_{2}$ at $2 \%$ on weight of resin solids

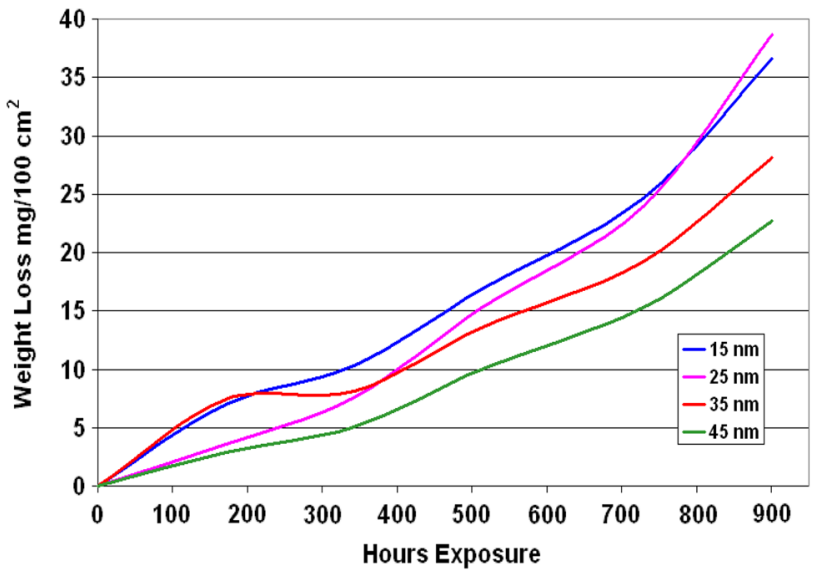

Fig. 6 Weight loss of an isocyanate acrylic coating containing $\mathrm{TiO}_{2}$ of various crystallite sizes

photocatalysis to occur at the pigment polymer interfaces leading to degradation of the coating, seen as weight loss.

It is apparent that the choice of size of $\mathrm{TiO}_{2}$ is a compromise between UVA absorption, visible transmission, surface area and hence photoactivity. Increasing the particle size, decreases the surface area and therefore reduces the amount of photoactive surface which causes the degradation of the surrounding polymer. Increasing the particle size also increases the amount of UVA radiation absorbed and scattered, which is beneficial in terms of protecting polymers. However, the disadvantage is the increase in the visible light absorption, the 'clear' paint film looks cloudy in appearance compared to those films made with smaller $\mathrm{TiO}_{2}$ as displayed in Scheme 1.

It is concluded that that there is no one size which is ideal, the choice of $\mathrm{TiO}_{2}$ size is a compromise, if a clear coating is desired, a smaller crystallite sized $\mathrm{TiO}_{2}$ must be chosen but at the risk of a less durable coating. However, it is proposed that with optimum preparation and adequate surface treatment that a large range of sizes could be used to shield UV in practice. For this reason, work has focussed on $\mathrm{TiO}_{2}$ with crystallite sizes between 15 and $35 \mathrm{~nm}$. (From the B.E.T.

$15 \mathrm{~nm}$ Crystallite size $45 \mathrm{~nm}$

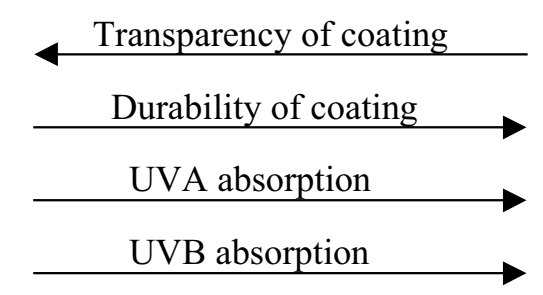

Scheme 1 Summary of the effect of crystallite size on transparency, durability and UV absorption properties of the coating 
surface area of these products, the particle size has been calculated as between 24 and $46 \mathrm{~nm}$ respectively.)

\section{Influence of Dispersant on Titanium Dioxide Nano-particles}

Initially, the $15 \mathrm{~nm}$ base $\mathrm{TiO}_{2}$ was milled with a variety of dispersants using a horizontal bead-mill manufactured by Netzsch. The following pre-treatments are widely utilised before application of the surface treatment of the blocker coatings. Dispersant levels were dependent upon the surface area of the $\mathrm{TiO}_{2}$ to be dispersed. A range of dispersants was successfully used to disperse and mill the $\mathrm{TiO}_{2}$. Both organic and inorganic dispersants were used; 2-amino-2-methyl-1-propanol (AMP) and 1-amino-2-propanol (MIPA) and $\mathrm{P}_{2} \mathrm{O}_{5}$ and $\mathrm{Na}_{2} \mathrm{SiO}_{3}$ respectively:

MIPA, AMP, $\mathrm{HCl} /\left(\mathrm{ZrOCl}_{2}\right), \mathrm{ZrOCl}_{2}, \mathrm{P}_{2} \mathrm{O}_{5} /(\mathrm{AMP}), \mathrm{Na}_{2} \mathrm{SiO}_{3}$

The dispersant demands will of course vary depending upon the crystal size of the particles as shown in Table 1 (omitting the $45 \mathrm{~nm}$ sample).

The micronised samples were evaluated in this test to assess the photoactivity, the higher the level of acetone generated the higher the photoactivity which as stated is said to be due to the fact that the oxidation of the IPA proceeds by using hydroxyl radicals, which are generated at the surface of the $\mathrm{TiO}_{2}$ when irradiated by UV light. If the surface of the $\mathrm{TiO}_{2}$ is adequately coated by other inorganic oxide layers which provide recombination centres for the photogenerated electron and hole pair this helps prevent the production of a hydroxyl radical at the valence band and hence prevents the oxidation of IPA.

The added surface treatment has reduced the photoactivity of the $\mathrm{TiO}_{2}$ as indicated by a lower ppm of acetone for those surface treated samples compared to the base $\mathrm{TiO}_{2}$, 20-50 ppm and 768 ppm respectively (Table 2). There is a variation in the results depending upon which dispersant was employed. The sample prepared on silicate milled base is the least photoactive (20 ppm) whilst the result obtained for the sample prepared on the phosphate milled base indicates the highest activity of the samples $(50 \mathrm{ppm})$. This may be an indication of how well the $\mathrm{SiO}_{2}$ layer has been able to precipitate onto the surface of the $\mathrm{TiO}_{2}$. These results suggest that the product made on the silicate milled base will be the most durable.

\section{Durability of the Coatings Prepared with Dispersant Treated Nano-particles}

The coated panels were exposed in the Atlas weatherometer for approximately $2500 \mathrm{~h} .60^{\circ}$ gloss and the weight loss of the coating were recorded over that exposure period. The weight loss of the coating with weathering is an indication
Table 1 Dispersant demands for $\mathrm{TiO}_{2}$ of various crystallite sizes

Table 2 Parts per million (ppm) of acetone generated in the isopropyl alcohol oxidation test for micronised surface treated $15 \mathrm{~nm} \mathrm{TiO}_{2}$

\begin{tabular}{llllc}
\hline & $\mathrm{pH}$ & $15 \mathrm{~nm} \mathrm{TiO}_{2}$ & $25 \mathrm{~nm} \mathrm{TiO}_{2}$ & $35 \mathrm{~nm} \mathrm{TiO}_{2}$ \\
\hline $\begin{array}{l}\text { Calgon } \\
\text { quoted as \% } \mathrm{P}_{2} \mathrm{O}_{5}\end{array}$ & 9 & 1.15 & 0.67 & 0.52 \\
$\%$ AMP-95 & 9 & 0.91 & 1.06 & 2.31 \\
$\begin{array}{l}\text { Sodium silicate } \\
\text { quoted as \% } \mathrm{SiO}_{2}\end{array}$ & 9 & 0.62 & 0.63 & 1.08 \\
$\begin{array}{l}\text { Zirconyl chloride }\left(\mathrm{ZrOCl}_{2}\right) \\
\text { quoted as \% } \mathrm{ZrO} 2\end{array}$ & 2.5 & 0.14 & Not determined & 0.19 \\
$\begin{array}{l}\text { Zirconyl chloride }\left(\mathrm{ZrOCl}_{2}\right) \\
\text { quoted as \% } \mathrm{ZrO} 2\end{array}$ & 4.3 & 0.22 & 0.31 & 0.45 \\
$\begin{array}{l}\text { Surface area, B.E.T } \\
\left(\mathrm{m}^{2} / \mathrm{g}\right)\end{array}$ & & 65.9 & 43.5 & 35.4 \\
\hline
\end{tabular}

\begin{tabular}{lc}
\hline Dispersant used to mill $\mathrm{TiO}_{2}$ prior to surface treatment with $\mathrm{SiO}_{2} / \mathrm{P}_{2} \mathrm{O}_{5} / \mathrm{Al}_{2} \mathrm{O}_{3}$ & $\begin{array}{l}\text { Parts per million (ppm) } \\
\text { acetone generated in IPA } \\
\text { test }\end{array}$ \\
\hline $\mathrm{Na}_{2} \mathrm{SiO}_{3}$ & 20 \\
$\mathrm{AMP}$ & 43 \\
$\mathrm{MIPA}$ & 37 \\
$\mathrm{ZrOCl}$ & 44 \\
$\mathrm{HCl} /(\mathrm{ZrOCl}$ & \\
$\mathrm{P}_{2} \mathrm{O}_{5} /(\mathrm{AMP})$ & 28 \\
$\mathrm{Base}_{\mathrm{TiO}}-$ no dispersant, not milled, not surface treated & 50 \\
\end{tabular}


of the extent of degradation, by measuring the degree of erosion of the coating. Photodegradation of the paint as well as photocatalytic degradation, causes the coating to break down, resulting in an increase in weight loss of that film with exposure.

After $900 \mathrm{~h}$ exposure the blank coating, i.e. with no $\mathrm{TiO}_{2}$, failed and the weight loss was due not only to the oxidation of the film but also to the paint peeling, pieces of the film became detached from the test panel because it had become so brittle. Up to this point, the weight loss was attributed to photodegradation only, since no $\mathrm{TiO}_{2}$ was employed in this paint. The weight losses recorded for the $\mathrm{TiO}_{2}$ containing coatings are due to both photodegradation of the polymer and the photocatalytic degradation caused by the presence of the $\mathrm{TiO}_{2}$. The weight loss of the $\mathrm{TiO}_{2}$ containing paints over and above that of the blank can be said to be due to the photoactivity of the $\mathrm{TiO}_{2}$ as shown in Table 3 .

Based on this data it is possible to conclude that the presence of the nanoparticle $\mathrm{TiO}_{2}$ has offered some protection to the polymeric coating as indicated by a lower weight loss for the coatings containing nano- $\mathrm{TiO}_{2}$ than that of the blank coating. Since the nano-TiO ${ }_{2}$ absorbs and scatters UV light that would otherwise be harmful to the polymeric coating, it is suggested that the nano- $\mathrm{TiO}_{2}$ is acting as a UV blocker. The dispersant used for milling the $\mathrm{TiO}_{2}$ has affected the weight loss of the coatings, they can be ranked in the following order, with the best for durability first (lowest weight loss):

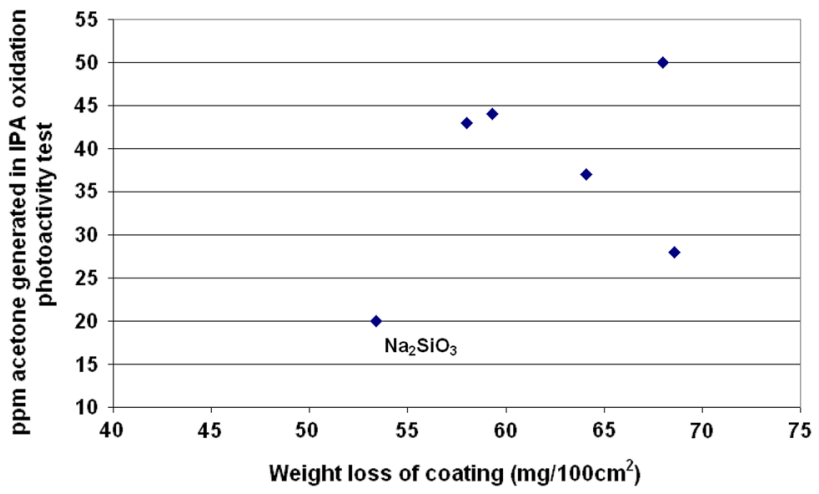

Fig. 7 Parts per million (ppm) acetone generated in the IPA oxidation test for photoactivity versus weight loss of isocyanate acrylic coating containing the UV blockers

variants, no correlation was possible between the ppm acetone generated in the IPA test and the weight loss of the coating containing the $\mathrm{TiO}_{2}$ as shown in Fig. 7.

\section{$60^{\circ}$ Gloss Loss of Weathered Coatings}

Since each of the coatings had a slightly different starting $60^{\circ}$ gloss, the results have been normalised and are shown as a $\%$ gloss retention of the initial reading over exposure time. Gloss reduces over time due to the surface roughness changing with weathering, as the surface of the paint film degrades the surface becomes rougher and this is recorded as a lower gloss. Data are compared and tabulated in Table 4

$\mathrm{Na}_{2} \mathrm{SiO}_{3}>\mathrm{AMP}=\mathrm{ZrOCl}_{2}>\mathrm{MIPA}>\mathrm{HCl} /\left(\mathrm{ZrOCl}_{2}\right)=\mathrm{P}_{2} \mathrm{O}_{5} /(\mathrm{AMP})$.

The weight loss results confirm the prediction from the IPA oxidation test, that the product made on $\mathrm{Na}_{2} \mathrm{SiO}_{3}$ milled base was the most durable, this product had produced the lowest ppm of acetone in the IPA test, indicating the lowest photoactivity. However, this was not true for the remaining for 1000 and $2000 \mathrm{~h}$ irradiated respectively.

Again, no direct comparison between the blank and the coatings containing the UV blocker $\mathrm{TiO}_{2}$ can be made as the blank failed early in the test. Since the gloss retention of all of the coatings is very similar after the total exposure time
Table 3 Weight loss $\left(\mathrm{mg} / 100 \mathrm{~cm}^{2}\right)$ of isocyanate acrylic coatings after 888 and $2332 \mathrm{~h}$ Atlas exposure containing UV blocker products prepared from base $\mathrm{TiO}_{2}$ milled with various dispersants prior to surface treatment with $\mathrm{SiO}_{2} / \mathrm{P}_{2} \mathrm{O}_{5} / \mathrm{Al}_{2} \mathrm{O}_{3}$ and micronised

\begin{tabular}{lrc}
\hline $\begin{array}{l}\text { Dispersant used to mill } \mathrm{TiO}_{2} \text { prior to surface treat- } \\
\text { ment with } \mathrm{SiO}_{2} / \mathrm{P}_{2} \mathrm{O}_{5} / \mathrm{Al}_{2} \mathrm{O}_{3}\end{array}$ & $888 \mathrm{~h}$ & $2332 \mathrm{~h}$ \\
\hline $\mathrm{Na}_{2} \mathrm{SiO}_{3}$ & 9.3 & 53 \\
$\mathrm{AMP}$ & 11.9 & 56 \\
$\mathrm{MIPA}$ & 12.4 & 64 \\
$\mathrm{ZrOCl}$ & 11.2 & 59 \\
$\mathrm{HCl} /\left(\mathrm{ZrOCl}_{2}\right)$ & 12.2 & 68 \\
$\mathrm{P}_{2} \mathrm{O}_{5} /(\mathrm{AMP})$ & 12.4 & 67 \\
$\mathrm{Base} \mathrm{TiO}_{2}$-no dispersant, not milled, not surface & 11.8 & 100 \\
treated & & \\
\hline
\end{tabular}

Table 4 Gloss retention of isocyanate acrylic coatings containing UV blocker products prepared from base $\mathrm{TiO}_{2}$ milled with various dispersants prior to surface treatment with $\mathrm{SiO}_{2} / \mathrm{P}_{2} \mathrm{O}_{5} / \mathrm{Al}_{2} \mathrm{O}_{3}$ and micronized after 1000 and $2000 \mathrm{~h}$ Weathering

\begin{tabular}{lll}
\hline $\begin{array}{l}\text { Dispersant used to mill } \mathrm{TiO}_{2} \text { prior to surface treat- } \\
\text { ment with } \mathrm{SiO}_{2} / \mathrm{P}_{2} \mathrm{O}_{5} / \mathrm{Al}_{2} \mathrm{O}_{3}\end{array}$ & $1000 \mathrm{~h}$ & $2000 \mathrm{~h}$ \\
\hline $\mathrm{Na}_{2} \mathrm{SiO}_{3}$ & 82 & 48 \\
$\mathrm{AMP}$ & 70 & 22 \\
$\mathrm{MIPA}$ & 71 & 21 \\
$\mathrm{ZrOCl}$ & 73 & 20 \\
$\mathrm{HCl} /\left(\mathrm{ZrOCl}_{2}\right)$ & 72 & 23 \\
$\mathrm{P}_{2} \mathrm{O}_{5} /(\mathrm{AMP})$ & 75 & 22 \\
Base $\mathrm{TiO}_{2}$-no dispersant, not milled, not surface & 92 & Failed \\
treated & & \\
\hline
\end{tabular}


by taking the time taken for the gloss retention to reach $60 \%$ of the original value, this can be used as an indication of the gloss loss rate and used to rank the performance of the products. The experimental products can be ranked in the following order using this method (most durable first, those which retain $60 \%$ gloss for the longest exposure period):
In the case of $\mathrm{P}_{2} \mathrm{O}_{5}$ it is suspected that the negative charge of phosphate anions stabilising the $\mathrm{TiO}_{2}$ slurry could prevent the precipitation of negatively charged silicate anions. To check if the addition point of $\mathrm{P}_{2} \mathrm{O}_{5}$ was critical to the overall performance of the final product, $4 \mathrm{UV}$ blockers were prepared; $\mathrm{P}_{2} \mathrm{O}_{5}$ was employed as a dispersant, but at dif-

$\mathrm{Na}_{2} \mathrm{SiO}_{3}>\mathrm{P}_{2} \mathrm{O}_{5} /(\mathrm{AMP})>\mathrm{HCl} /\left(\mathrm{ZrOCl}_{2}\right)=$ MIPA $>$ AMP $>\mathrm{ZrOCl}_{2}$.

Whilst these data represent the titania crystal size of $15 \mathrm{~nm}$ the overall blocking efficacy will be determined by the crystallite size of the $\mathrm{TiO}_{2}$, the density and type of surface treatment, the effect of the base $\mathrm{TiO}_{2}$ size and the effect of micronising on the dispersibility of the finished products, if the dispersion can be improved, the durability should also improve as a more efficient shielding of UV should be obtainable when the particles are finely distributed throughout the matrix.

\section{Role of Surface Treatment and Density}

The ratios and types of surface treatments and order of precipitation are mostly propriety amongst manufacturers but in this study they have been previously optimised at Millennium Chemicals [27-29]. Thus, the role of the surface treatment type and density on the longevity of the coating in which the $\mathrm{TiO}_{2}$ is to be added is a further important feature of the whole Titania coating process. Two different types of surface treatment at two different densities have been evaluated. This study had shown that a slightly larger $\mathrm{TiO}_{2}$ with crystallite size of $25 \mathrm{~nm}$ exhibited better shielding of UVA radiation than $15 \mathrm{~nm}$ crystallites. The larger the crystallites, the lower the surface area, therefore the level of surface treatment, $10 \%$ weight on $\mathrm{TiO}_{2}$ should cover the surface of a $\mathrm{TiO}_{2}$ with crystallite size of $25 \mathrm{~nm}$ more adequately than would be the case for the $15 \mathrm{~nm} \mathrm{TiO}_{2}$. This work also confirms the effect of the size of the $\mathrm{TiO}_{2}$ since the same surface treatment which was employed in the dispersant work was also employed here, based on $\mathrm{SiO}_{2}, \mathrm{Al}_{2} \mathrm{O}_{3}$ and $\mathrm{P}_{2} \mathrm{O}_{5}$. The second type of treatment evaluated was based on $\mathrm{ZrO}_{2}, \mathrm{Al}_{2} \mathrm{O}_{3}$ and $\mathrm{P}_{2} \mathrm{O}_{5}$. Earlier workers reported on the role and density of alumina/silica coatings on dispersibility and photoactivity by monitoring methylene blue bleaching [30]. Here silica played a controlling influence.

An ingredient common to both surface treatments is $\mathrm{P}_{2} \mathrm{O}_{5}$, but as $\mathrm{Na}_{2} \mathrm{SiO}_{3}$ gives a more durable product, for this experiment $\mathrm{SiO}_{2}$ was only required for one of the surface treatment variants, therefore $\mathrm{Na}_{2} \mathrm{SiO}_{3}$ could not be used as a dispersant. A reason for the possible differences between the samples prepared on $\mathrm{TiO}_{2}$ which had been milled with different dispersants was that the dispersant prevented the $\mathrm{SiO}_{2}$ from depositing onto the $\mathrm{TiO}_{2}$ surface very effectively. fering levels, $0,0.4,0.66$ and $0.8 \%$. Since the total level of $\mathrm{P}_{2} \mathrm{O}_{5}$ added for the treatment recipe was $0.8 \%$, this was the maximum used and for the least, $0 \%, \mathrm{Na}_{2} \mathrm{SiO}_{3}$ was used as a dispersant. This would enable the precipitation of $\mathrm{SiO}_{2}$ onto $\mathrm{TiO}_{2}$ with different levels of $\mathrm{P}_{2} \mathrm{O}_{5}$ present and establish if the end product differed because of it. This would also confirm whether $\mathrm{SiO}_{2}$ can precipitate onto $\mathrm{TiO}_{2}$ which had been milled with $\mathrm{P}_{2} \mathrm{O}_{5}$ as well as it could onto $\mathrm{TiO}_{2}$ which had been milled with silicate.

The resulting UV blockers were added to an isocyanate acrylic coating by the method already described at a level of $2 \%$ weight on the resin solids of the dried clear coat. The paints were then spun coated onto stainless steel, dried and exposed in the Atlas weatherometer for a period of approximately $2500 \mathrm{~h}$. Weight loss was recorded throughout the exposure period. Both the presence of $\mathrm{P}_{2} \mathrm{O}_{5}$ and the quantity in which it is present prior to the $\mathrm{SiO}_{2}$ being precipitated do not affect the performance of the final product in the isocyanate acrylic coating. All the variants exhibit a similar weight loss in the range $47-50 \mathrm{mg} / 100 \mathrm{~cm}^{2}$, indicating that the $\mathrm{SiO}_{2}$ has been precipitated in a similar fashion in all of the variants, irrespective of the presence of $\mathrm{P}_{2} \mathrm{O}_{5}$ or the quantity (Fig. 8).

Work with smaller crystallite $\mathrm{TiO}_{2}(15 \mathrm{~nm})$ had suggested that the best (least) weight loss was achieved when $\mathrm{SiO}_{2}$ was employed as the dispersant and that $\mathrm{P}_{2} \mathrm{O}_{5}$ was not as good.

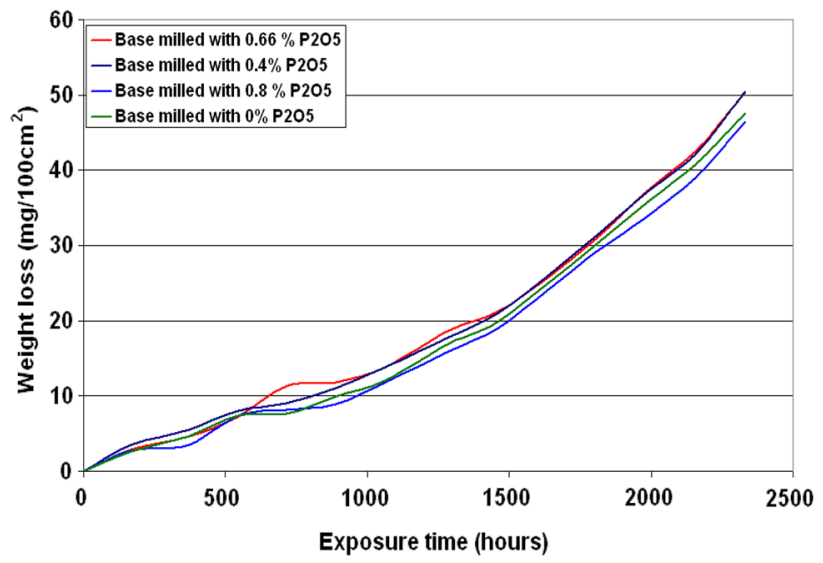

Fig. 8 Weight loss of isocyanate acrylic containing UV blocker products prepared from base $\mathrm{TiO}_{2}$ milled with varying levels of $\mathrm{P}_{2} \mathrm{O}_{5}$ 
Here both silicate and phosphate have been compared again but on slightly larger $\mathrm{TiO}_{2}$, these results show that there is no difference in durability of the products prepared on silicate or phosphate milled base $\mathrm{TiO}_{2}$. A probable explanation for this difference is that the surface treatment level (at $10 \%$ weight on $\mathrm{TiO}_{2}$ ) is sufficient to reduce the photoactivity of this $25 \mathrm{~nm}$ base. For the $25 \mathrm{~nm} \mathrm{TiO}_{2}$ base, the surface area was $40 \mathrm{~m}^{2} / \mathrm{g}$, therefore the surface treatment per unit of surface area was $0.26 \% / \mathrm{m}^{2}$, compared to just $0.14 \% / \mathrm{m}^{2}$ for the $15 \mathrm{~nm}$ samples. This level is now probably sufficient to reduce the photoactivity and the differences are not so marked. It was clear from this data that phosphate could be used to mill the base $\mathrm{TiO}_{2}$ prior to treatment and would not adversely affect the way in which the $\mathrm{SiO}_{2}$ would precipitate as part of the $\mathrm{SiO}_{2} / \mathrm{Al}_{2} \mathrm{O}_{3} / \mathrm{P}_{2} \mathrm{O}_{5}$ treatment.

\section{Effect of Surface Treatment Type and Density}

Two different types of surface treatment were investigated; $\mathrm{SiO}_{2} / \mathrm{Al}_{2} \mathrm{O}_{3} / \mathrm{P}_{2} \mathrm{O}_{5}$ (already used in the dispersant work) and another type based on $\mathrm{ZrO}_{2} / \mathrm{Al}_{2} \mathrm{O}_{3} / \mathrm{P}_{2} \mathrm{O}_{5}$, abbreviated to $\mathrm{Si} /$ $\mathrm{Al} / \mathrm{P}$ and $\mathrm{Zr} / \mathrm{Al} / \mathrm{P}$ respectively for ease. Two levels were used for each; $\mathrm{Si} / \mathrm{Al} / \mathrm{P}$ treatment at 10 and $20 \%$ weight on $\mathrm{TiO}_{2}$ and $\mathrm{Zr} / \mathrm{Al} / \mathrm{P}$ at 5.3 and $10.6 \%$ weight on $\mathrm{TiO}_{2}$. It is known within the $\mathrm{TiO}_{2}$ industry that to successfully precipitate a "dense" layer of $\mathrm{SiO}_{2}$ around the $\mathrm{TiO}_{2}$ core particle which will successfully suppress the photoactivity, a high temperature along with a long neutralisation/precipitation time is favourable [31, 32]. Within this experiment a neutralisation time of 60 min was employed, but also included for comparison was a $10.2 \% \mathrm{Si} / \mathrm{Al} / \mathrm{P}$ treated product where the $\mathrm{SiO}_{2}$ was precipitated over a shorter time of $40 \mathrm{~min}$, to see if the shorter precipitation time gave rise to a less durable product.

Furthermore, also included for comparison, a sample was prepared by adding just $2 \% \mathrm{Al}_{2} \mathrm{O}_{3}$, the purpose of which was to evaluate the performance of the base $\mathrm{TiO}_{2}$ without any surface treatment. The $2 \% \mathrm{Al}_{2} \mathrm{O}_{3}$ was added to aid dispersion in the Isocyanate Acrylic coating, this level of surface treatment will have a minimal effect on the photoactivity. Including this sample enabled a comparison of non-treated and surface treated $\mathrm{TiO}_{2}$, allowing the efficiency of the added surface treatment to be assessed.

The non-micronised products were dry ground using a coffee mill and added to a clear isocyanate acrylic coating at a level of $2 \%$ based on the weight of the resin solids by the method previously described. The paints were applied to panels and exposed in the Atlas weatherometer, weight loss and gloss was recorded over the exposure period.

The experimental products can be ranked in the following order (most durable first, those which retain $60 \%$ gloss and least weight loss for the longest exposure period):

$20 \% \mathrm{Si} / \mathrm{Al} / \mathrm{P}>10 \% \mathrm{Si} / \mathrm{Al} / \mathrm{P}>5 \% \mathrm{Zr} / \mathrm{Al} / \mathrm{P}>2 \% \mathrm{Al}$
Table $5 \%$ Gloss retention and Weight loss $\left(\mathrm{mg} / 100 \mathrm{~cm}^{2}\right)$ of isocyanate acrylic coatings containing UV blocker products surface treated with various oxides, non-micronised

\begin{tabular}{|c|c|c|c|}
\hline \multirow{2}{*}{$\begin{array}{l}\text { Surface treatments } \\
\text { with } \mathrm{SiO}_{2} / \mathrm{P}_{2} \mathrm{O}_{5} / \\
\mathrm{Al}_{2} \mathrm{O}_{3}\end{array}$} & $\begin{array}{l}\text { Weight loss } \\
\left(\mathrm{mg} / 100 \mathrm{~cm}^{2}\right)\end{array}$ & Gloss retention & Gloss retention \\
\hline & $2366 \mathrm{~h}$ & $1000 \mathrm{~h}$ & $2000 \mathrm{~h}$ \\
\hline $5.3 \% \mathrm{Zr} / \mathrm{Al} / \mathrm{P}$ & 71 & 92 & 80 \\
\hline $20.4 \% \mathrm{Si} / \mathrm{Al} / \mathrm{P}$ & 47 & 75 & 87 \\
\hline $10.2 \% \mathrm{Si} / \mathrm{Al} / \mathrm{P}$ & 57 & 94 & 84 \\
\hline $2 \% \mathrm{Al}$ & 80 & 82 & 20 \\
\hline Blank & 105 & 81 & 18 \\
\hline
\end{tabular}

Table $6 \%$ Gloss retention and weight loss $\left(\mathrm{mg} / 100 \mathrm{~cm}^{2}\right)$ of isocyanate acrylic coatings containing UV blocker products surface treated with various oxides, micronised

\begin{tabular}{|c|c|c|c|}
\hline $\begin{array}{l}\text { Surface treat- } \\
\text { ments with }\end{array}$ & $\begin{array}{l}\text { Weight loss } \\
\left(\mathrm{mg} / 100 \mathrm{~cm}^{2}\right)\end{array}$ & $\begin{array}{l}\% \text { Gloss reten- } \\
\text { tion }\end{array}$ & $\%$ Gloss retention \\
\hline $\begin{array}{l}\mathrm{SiO}_{2} / \mathrm{P}_{2} \mathrm{O}_{5} / \\
\mathrm{Al}_{2} \mathrm{O}_{3}\end{array}$ & $2332 \mathrm{~h}$ & $1000 \mathrm{~h}$ & $2000 \mathrm{~h}$ \\
\hline $5.3 \% \mathrm{Zr} / \mathrm{Al} / \mathrm{P}$ & 65 & 91 & 80 \\
\hline $20.4 \% \mathrm{Si} / \mathrm{Al} / \mathrm{P}$ & 50 & 92 & 63 \\
\hline $10.6 \% \mathrm{Zr} / \mathrm{Al} / \mathrm{P}$ & 63 & 93 & 63 \\
\hline $10.2 \% \mathrm{Si} / \mathrm{Al} / \mathrm{P}$ & 63 & 80 & 61 \\
\hline Blank & Destroyed & 81 & Destroyed \\
\hline
\end{tabular}

Gloss retention data and weight loss are shown in Table 5 for comparison for non-micronised samples.

The addition of surface treatments to the experimental products has suppressed the photoactivity of the $\mathrm{TiO}_{2}$ as indicated by a lower weight loss compared to both the blank unstabilised coating as well as the coating containing the base $\mathrm{TiO}_{2}$ with just $2 \% \mathrm{Al}_{2} \mathrm{O}_{3}$.

Both the type of surface treatment and the level at which it is added is of importance to the performance of the product in the isocyanate acrylic coating. The treatment based on $\mathrm{Zr} / \mathrm{Al} / \mathrm{P}$ is inferior to that based on $\mathrm{Si} / \mathrm{Al} / \mathrm{P}$ although the treatment level was lower and as such firm conclusions cannot be made from this data about the efficiency of the $\mathrm{Zr}$ / $\mathrm{Al} / \mathrm{P}$ treatment compared to the $\mathrm{Si} / \mathrm{Al} / \mathrm{P}$ counterpart.

For the treatment based on $\mathrm{Si} / \mathrm{Al} / \mathrm{P}$, increasing the level of the surface treatment increases the durability and the coatings undergo less photodegradation where the higher surface treatment level is employed. Average weight loss for the $10.2 \%$ treatment level is $57 \%$ compared to just $47 \%$ weight loss when a higher treatment level of $20.4 \%$ is employed.

Gloss retention and weight loss of coatings containing the micronised variants were evaluated in the same manner as the non-micronised variants and the data shown in Table 6 respectively only this time omitting the $2 \% \mathrm{Al}$ due to its poor performance. 
The experimental products can be ranked in the following order (most durable first, those which retain $60 \%$ gloss for the longest exposure period):
In general, the presence of surface treated nano-sized $\mathrm{TiO}_{2}$ enhances the lifetime of the isocyanate acrylic coating as indicated by a lower weight loss for the coatings

$5 \% \mathrm{Zr} / \mathrm{Al} / \mathrm{P}>20 \% \mathrm{Si} / \mathrm{Al} / \mathrm{P}=10 \% \mathrm{Zr} / \mathrm{Al} / \mathrm{P}=10 \% \mathrm{Si} / \mathrm{Al} / \mathrm{P}>$ Blank

The data is extremely close and there is not much discrimination between the samples in actual fact.

The blank coating was so non-durable that the coating rapidly starts to come away from the panel. The weight loss rises rapidly at the point where pieces of film begin to break away from the bulk, after which point it is not meaningful to record the weight loss of the coating.

After $2332 \mathrm{~h}$ Atlas exposure Table 6, the experimental products can be ranked in the following order, with the lowest weight loss first indicating the most durable: containing $\mathrm{TiO}_{2}$ than the blank coating. The extent to which protection has been offered depends upon the crystallite size, the surface treatment type and level added.

When comparing the same surface treatment type and level; $10 \%$ weight on $\mathrm{TiO}_{2}$, comprising of $\mathrm{SiO}_{2} / \mathrm{Al}_{2} \mathrm{O}_{3} /$ $\mathrm{P}_{2} \mathrm{O}_{5}$, on both 15 and $25 \mathrm{~nm}$ base $\mathrm{TiO}_{2}$, the weight loss of the coating containing the latter was less, indicating better durability, than the former. This could be due to the surface treatment per square metre of surface area of $\mathrm{TiO}_{2}$ being higher for the $25 \mathrm{~nm} \mathrm{TiO}_{2}$, or that the $25 \mathrm{~nm}$ particles of

$20 \% \mathrm{Si} / \mathrm{Al} / \mathrm{P}>10 \% \mathrm{Zr} / \mathrm{Al} / \mathrm{P}=10 \% \mathrm{Si} / \mathrm{Al} / \mathrm{P}>5 \% \mathrm{Zr} / \mathrm{Al} / \mathrm{P}>$ Blank

The results are consistent with the non-micronised variants, and as such the same conclusions can be drawn.

\section{Comparison of $\mathrm{SiO}_{2} / \mathrm{Al}_{2} \mathrm{O}_{3} / \mathrm{P}_{2} \mathrm{O}_{5}$ Treatment on 15 and $25 \mathrm{~nm}$ Base $\mathrm{TiO}_{2}$}

Figure 9 shows the weight loss of the isocyanate acrylic coating containing the UV blocker products prepared on different sized base $\mathrm{TiO}_{2}$ with the same surface treatment, $10 \%$ weight on $\mathrm{TiO}_{2} ; \mathrm{SiO}_{2} / \mathrm{Al}_{2} \mathrm{O}_{3} / \mathrm{P}_{2} \mathrm{O}_{5}$. The $\%$ treatment per square meter of $\mathrm{TiO}_{2}$ surface for the $15 \mathrm{~nm}$ and $25 \mathrm{~nm}$ base is 0.14 and $0.25 \%$ respectively. The weight loss of the large crystallite sized $\mathrm{TiO}_{2}$ is less than that for the $15 \mathrm{~nm}$ variant, when both $\mathrm{Na}_{2} \mathrm{SiO}_{3}$ and $\mathrm{P}_{2} \mathrm{O}_{5}$ were employed as dispersants.

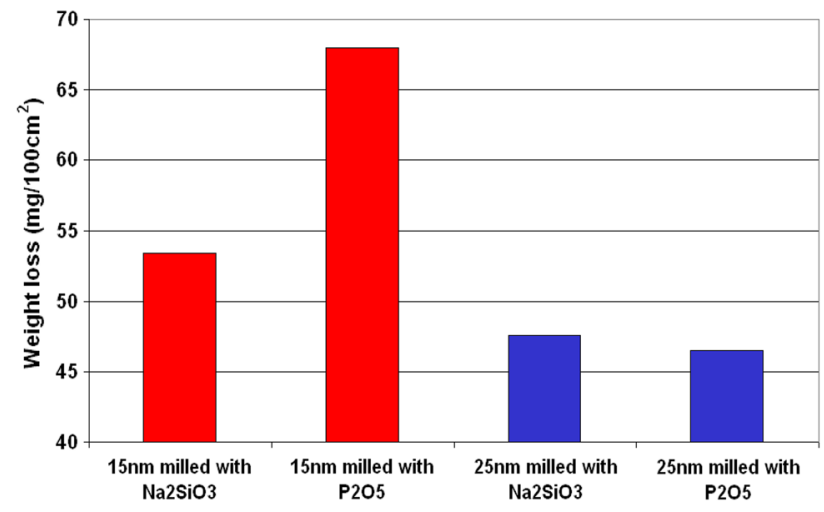

Fig. 9 Weight loss of isocyanate acrylic coatings containing UV blocker products surface treated with $\mathrm{SiO}_{2} / \mathrm{Al}_{2} \mathrm{O}_{3} / \mathrm{P}_{2} \mathrm{O}_{5}$ after $2332 \mathrm{~h}$ Atlas exposure
$\mathrm{TiO}_{2}$ blocks the UVA radiation better than the smaller $\mathrm{TiO}_{2}$ of $15 \mathrm{~nm}$, or a combination of the two factors.

At a level of $10 \mathrm{wt} \%$ on $\mathrm{TiO}_{2}$, surface treatments based on $\mathrm{ZrO}_{2} / \mathrm{Al}_{2} \mathrm{O}_{3} / \mathrm{P}_{2} \mathrm{O}_{5}$ and $\mathrm{SiO}_{2} / \mathrm{Al}_{2} \mathrm{O}_{3} / \mathrm{P}_{2} \mathrm{O}_{5}$ performed similarly. Raising the level of surface treatment to $20 \%\left(\mathrm{SiO}_{2} / \mathrm{Al}_{2} \mathrm{O}_{3} /\right.$ $\mathrm{P}_{2} \mathrm{O}_{5}$ surface treatment only) further improved the durability of the coating as determined by gloss retention and weight loss.

Figure 10 shows that there is a fairly good correlation between the weight loss of the coatings containing the micronised samples and those containing the non-micronised samples. Indicating that during the paint making process, there is enough energy used to break down aggregates and agglomerates, so that whether micronised or non-micronised product is used, the same performance results.

Figure 11 shows the correlation between weight loss in the exposed coating and the ppm of acetone generated

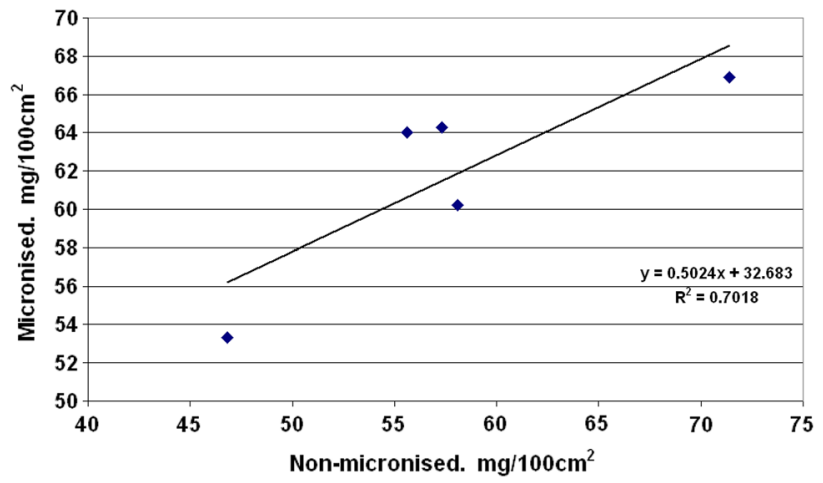

Fig. 10 Weight loss of isocyanate acrylic coatings containing UV blocker products surface treated with various mixed oxides, micronised vs. non-micronised after 2366 and $2332 \mathrm{~h}$ exposure respectively 


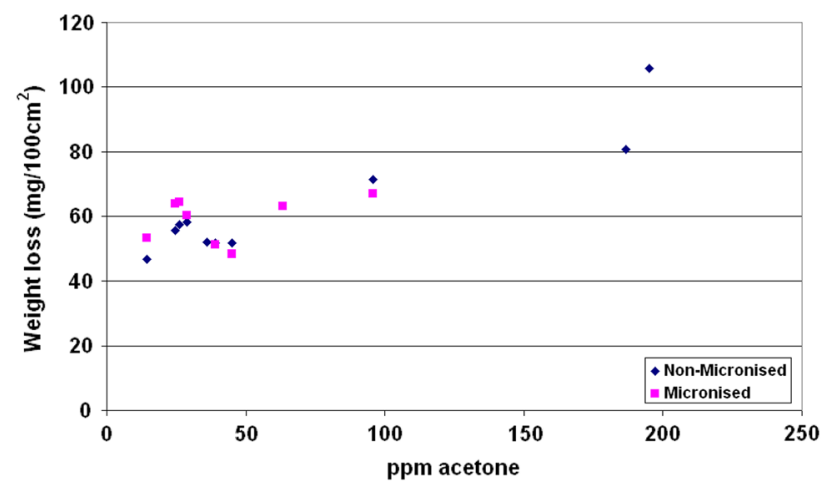

Fig. 11 Weight loss in an isocyanate acrylic coating versus ppm acetone generated in the IPA oxidation for various UV blocker products

in the isopropyl alcohol oxidation test. For the range over which acetone generation can vary between $\sim 25$ and $50 \mathrm{ppm}$ the weight loss of the coating was fairly constant. Those products which exhibited very poor durability also generated a higher amount of acetone in the IPA oxidation test. The IPA oxidation test seems to be able to predict a really bad performing UV Blocker, but is not good at differentiating between those which are fairly durable, i.e. those which exhibit an acetone generation up to approximately $50 \mathrm{ppm}$. This was also found in our previous investigation on nanoanatase particles.

\section{Conclusions}

All the surface treated $\mathrm{TiO}_{2}$ products were successful at acting as UV blockers in the isocyanate acrylic coatings. Products prepared using $\mathrm{Na}_{2} \mathrm{SiO}_{3}$ milled base were the most durable, as shown by the lowest weight loss results, which was correlated with the predictions of the IPA oxidation test. However, the weight loss of the remaining samples did not correlate at all with the ppm acetone generated in the IPA test, indicating that it cannot be used as an accurate predictor for durability here. In terms of durability, the non-micronised experimental products ranked in the same order as the micronised variants had done. UV/Visible absorption spectra for the thin films containing micronised UV blockers were very similar. For the non-micronised variants, the film containing the UV blocker prepared on the $\mathrm{Na}_{2} \mathrm{SiO}_{3}$ milled base $\mathrm{TiO}_{2}$ was not as transparent as the other experimental samples. This showed that micronising was beneficial to the $\mathrm{Na}_{2} \mathrm{SiO}_{3}$ milled base sample, enabling a similar optical film to the other experimental products. Of the non-micronised variants, the sodium silicate dispersed and $\mathrm{SiO}_{2}$ treated $\mathrm{TiO}_{2}$ exhibited a lower weight loss, but the optical properties were not as good as with the other dispersants in terms of UV/Visible absorption spectra. The silicate milled variant shows the highest absorbance at $550 \mathrm{~nm}$ in a thin film which means that the transparency of that film is poor and not aesthetically acceptable for a clear coating. The same low weight loss can be obtained when employing AMP as the dispersant and the transparency of that film is enhanced as shown by a low absorbance in the visible region of the spectrum, i.e. at $550 \mathrm{~nm}$.

Of the micronised variants, the silicate milled base also has the lowest weight loss but again followed extremely closely by the AMP variant which has better transparency. Product performance in terms of durability, of the surface treated $25 \mathrm{~nm}$ $\mathrm{TiO}_{2}$ with $\mathrm{SiO}_{2} / \mathrm{Al}_{2} \mathrm{O}_{3} / \mathrm{P}_{2} \mathrm{O}_{5}$ at a $10 \%$ weight on $\mathrm{TiO}_{2}$ level is the same when either $\mathrm{P}_{2} \mathrm{O}_{5}$ or $\mathrm{Na}_{2} \mathrm{SiO}_{3}$ are employed as a dispersant to mill the base $\mathrm{TiO}_{2}$. Previously, using $\mathrm{P}_{2} \mathrm{O}_{5}$ to mill the $15 \mathrm{~nm}$ base $\mathrm{TiO}_{2}$ prior to surface treatment with $10 \%$ $\mathrm{SiO}_{2} / \mathrm{Al}_{2} \mathrm{O}_{3} / \mathrm{P}_{2} \mathrm{O}_{5}$ had given a product inferior to that obtained when silicate was employed as the dispersant. It is concluded that differences in durability are likely to be due to the fact that the surface treatment level was not sufficient to deactivate the $15 \mathrm{~nm}$ base. When the same percentage of treatment was added to the $25 \mathrm{~nm}$ base the product performance was the same irrespective of whether $\mathrm{P}_{2} \mathrm{O}_{5}$ or $\mathrm{Na}_{2} \mathrm{SiO}_{3}$ was used as the dispersant. At an addition rate of $10 \%$ surface treatment on the weight of the $\mathrm{TiO}_{2}$, this equates to 0.14 and $0.26 \% / \mathrm{m}^{2}$ for the 15 and $25 \mathrm{~nm}$ bases respectively. In general, the presence of nano-sized $\mathrm{TiO}_{2}$ prolonged the lifetime of the isocyanate acrylic coating depending upon the crystallite size, the surface treatment type and level added. Presumably the surface treatment per square metre of surface area of $\mathrm{TiO}_{2}$ will be higher for the $25 \mathrm{~nm} \mathrm{TiO}_{2}$. This could also be associated with the fact that the $25 \mathrm{~nm}$ particles of $\mathrm{TiO}_{2}$ will block UVA radiation more effectively than the $15 \mathrm{~nm}$ particles. Raising the level of surface treatment to $20 \%\left(\mathrm{SiO}_{2} / \mathrm{Al}_{2} \mathrm{O}_{3} / \mathrm{P}_{2} \mathrm{O}_{5}\right.$ surface treatment only) further improved the durability of the coating as determined by gloss retention and weight loss.

In the case of the macro-grade (Rutile) titanium dioxide pigments their photo $=$ stabilising activity in alkyd paint film increased with the levels of Si/Al/Organic coatings and were found to be directly related to the electron-hole pair mobility and trapping efficacy as determined by micro-wave spectroscopy.

There are numerous recent publications investigating various ways in surface treating and impregnating nano-titania particles [33, 34]. Carbon coating for photostabilising PVC is particularly relevant while many other areas coat the particles for environmental biological systems. This work here provides yet another valuable technology for UV blocking applications in both paints and polymer systems.

Acknowledgements The authors thank Millenium Chemicals (now Cristal Global) for allowing one of the co-authors Claire Hill (neBygott) to submit part of this work for the degree of $\mathrm{PhD}$ at MMU. 


\section{References}

1. Yan X, Li Y, Xia T (2017) Int J Photoenergy 17:16

2. Allen NS, Mahdjoub N, Vishnyakov V, Kelly PJ, Kriek RJ (2018) Polym Degrad Stab 150:31

3. Fischer K, Gawel A, Rosen D, Krause M, Latif AA, Griebel J, Prager A, Schulze A (2017) Catalysts 7:209

4. Gurav A, Pluym T, Xiong T (1993) Aerosol Sci Technol 19:411

5. Balfour JG (1992) Fine particle $\mathrm{TiO}_{2}$, its properties and uses. Paper presented at SURCONY 91, New Material, 1:21

6. Prasai B, Cai B, Kylee Underwood M, Lewis JP, Drabold DA (2012) J Mater Sci 47:7515

7. Allen NS, Edge M, Ortega A, Liauw CM, Stratton J, McIntyre RB (2002) Polym Degrad Stab 78:467

8. Ribarsky MW (1985) Titanium dioxide $\left(\mathrm{TiO}_{2}\right)$ (rutile). In: Palik ED (ed) Hand book of optical constants of solids. Academic, New York, pp 795-804

9. Fields DP, Buchacek RJ, Dickinson JG (1993) J Oil Colour Chem Assoc 2:87

10. Luttrell T, Halpegamage S, Tao J, Kramer A, Sutter E, Batzill M (2014) Sci Rep 4:4043

11. Fujishima A, Rao TN, Tryk DA (2000) Electrochim Acta 45:4683

12. Gao L, Zhang Q (2001) Scripta Mater 44:1195

13. Xu W, Zhu S, Fu X (1998) J Phys Chem Solids 59(9):1647

14. Hoffmann MR, Martin SW, Choi W, Bahnemann DW (1995) Chem Rev 95:69

15. Anpo M, Shima T, Kodama S, Kubokawa Y (1987) J Phys Chem 91:4305
16. Jang H, Kim S,(2001) Mater Res Bull 36:627

17. Ye X, Jin Y, Lie G (2000) Proceedings of ICETS 2000-ISAM, October 11, Beijing, Session 3, 1:718

18. Millennium Chemicals, US Patent 6,656,261 B2

19. Allen NS, Chow YS, Thompson FF, Jewitt TS, Hornby MR (1991) Polym Degrad Stab 32:119

20. Chow YS, Allen NS, Thompson FF, Jewitt TS, Hornby MR, Simpson AL (1991) J Photochem Photobiol A Chem 60:369

21. Irick G, J (1972) Appl Polym Sci 16:2387

22. Allen NS, Edge M, Sandoval G, Ortega A, Liauw CM, Stratton J, McIntyre RB (2002) Polym Degrad Stab 76:305

23. Pappas SP, Kuhhirt W (1975) J Paint Technol 47:42

24. Voeltz HG, Kaempf G, Fitsky HG (1972) Prog Org Coat 14:1941

25. Balfour JG (1992) Polym Paint Colour J 182:283

26. Simpson LA (1986) Polym Paint Colour J 176:408

27. Patent US 6,695,906

28. Patent US 6,656,261

29. Patent US 6,395,081

30. van Dyk AC, Heyns AM (1998) J Collid Interface Sci 206:381

31. Iler RK (1959) US patent 2885366

32. Werner AJ (1969) US Patent 3437502

33. Sokhandani P, Adel Abdi M, Mehmandoust S, Babaluo AA, Mehdizadeh R, Rezaei S, Rakhshani M (2014) J Appl Polym Sci 131:243

34. Bogdan J, Jackowska-Tracz A, Zarzynska J, Plawinska-Czarnak J (2015) Nanoscale Res Letts 10:57 